\title{
A new case of TAR syndrome confirms the importance of noncoding variants in the etiopathogenesis of the disease.
}

\author{
Anna Morgan ${ }^{1}$, Savina Dipresa ${ }^{2}$, Licia Turolla ${ }^{2}$, Martina La Bianca $^{1}$, Flavio Faletra ${ }^{1}$, and \\ Giorgia Girotto ${ }^{1}$ \\ ${ }^{1}$ Institute for Maternal and Child Health - IRCCS, Burlo Garofolo \\ ${ }^{2}$ Medical Genetics Unit, Local Health Authority
}

September 30, 2020

\begin{abstract}
TAR syndrome is a rare congenital disorder whose genetic bases have remained unclear for many years. It has now been understood that the disease is caused by the compound inheritance of a rare null allele (usually the 1q21.1 deletion) and a low-frequency hypomorphic noncoding single nucleotide polymorphism (SNP) in RBM8A gene. Nevertheless, only a limited set of variants has been identified so far. A recent report of Boussion et al. described four novel RBM8A noncoding SNPs (i.e., 1) c. $\left.205+3 \_205+6 \mathrm{del}, 2\right)$ c. $\left.206-13 \mathrm{C}>\mathrm{A}, 3\right)$ c. $-19 \mathrm{G}>\mathrm{T}$, and 4) c. ${ }^{*} 6 \mathrm{C}>\mathrm{G}$ ) increasing the mutational spectrum of TAR syndrome. Here, based on the recently published manuscript by Boussion et al., we report data regarding an additional African TAR patient carrying the 1q21.1q21.2 deletion in trans with the 3 'UTR (c. ${ }^{*} 6 \mathrm{C}>\mathrm{G}$ ) variant. Present data further confirm the pathogenic role of this hypomorphic SNP and highlights its relevance in the African population, leading to advice geneticists to directly search for the c. ${ }^{*} 6 \mathrm{C}>\mathrm{G}$ variant in African patients affected by TAR syndrome and carrying the $1 \mathrm{q} 21.1$ deletion, shortening the diagnostic time window.
\end{abstract}

\section{Hosted file}

Letter_TAR_syndrome.pdf available at https://authorea.com/users/363090/articles/484000a-new-case-of-tar-syndrome-confirms-the-importance-of-noncoding-variants-in-theetiopathogenesis-of-the-disease
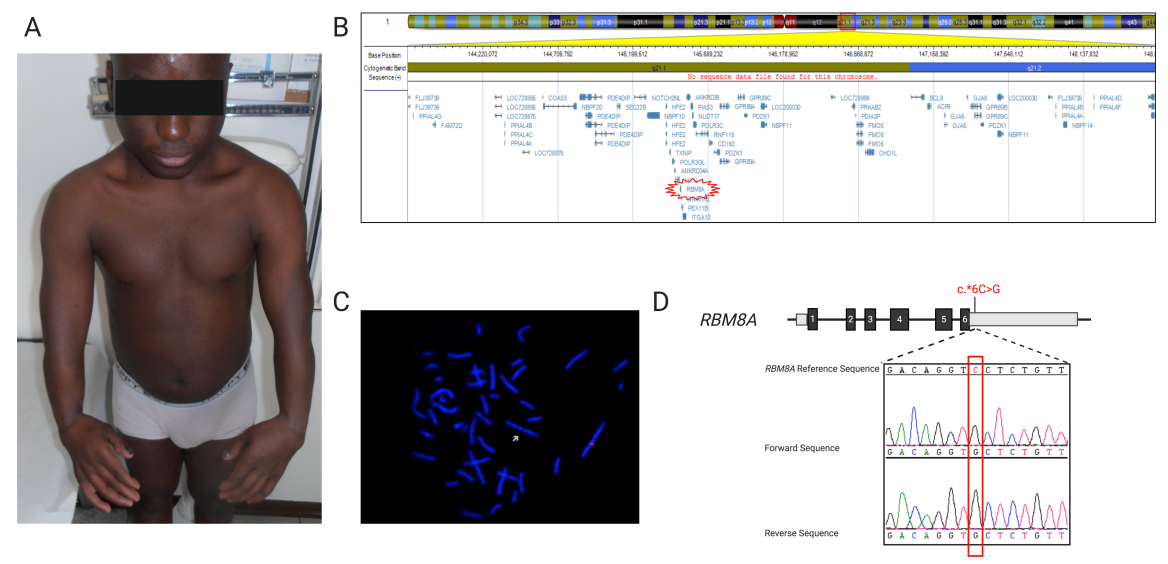